\title{
Visibly better? Testing the effect of ethnic appearance on citizen perceptions of the police
}

\author{
Tom Davies ${ }^{\mathrm{a} *}$, Ben Bradford ${ }^{\mathrm{b}}$, Julia A. Yesberg ${ }^{\mathrm{b}}$ and Krisztián Pósch ${ }^{\mathrm{c}}$
}

${ }^{a}$ Mayor's Office for Policing and Crime, London, UK; ${ }^{b}$ Jill Dando Institute of Security and Crime Science, University College London, UK; ${ }^{c}$ Department of Methodology, London School of Economics and Political Science, UK

*Tom Davies, Mayor's Office for Policing and Crime, City Hall, The Queen's Walk, London SE1 2AA, United Kingdom, +44 (0)7932 758468, tom.davies@mopac.london.gov.uk

\begin{abstract}
Ethnic minority officers continue to be underrepresented across UK police forces. Further, some ethnic minority groups consistently report lower levels of confidence in police compared to their White British counterparts. Although there is consensus that a more ethnically representative police service is a good idea, there is limited evidence in the UK on how the public perceives officers of different ethnic appearance, and how this relates to trust, confidence and legitimacy. This paper presents findings from an online experiment $(n=260)$ exploring how ethnic appearance affects perceptions of police. Our findings offer rare empirical support for a more ethnically representative police force. First, across respondents, we found that Black officers were perceived significantly more favourably than White or Asian officers. Second, we found that Black respondents had more negative responses to White officers, yet there was little evidence that Black officers elicited more negative reactions from White or Asian respondents. We discuss the theoretical and practical implications of the findings.
\end{abstract}

Keywords: policing; ethnic representation; police diversity; trust 


\section{Introduction}

Issues of ethnicity and race play a fundamental role in the politics and public perceptions of the police. The recent killing of Black American George Floyd by a police officer in the US sparked large scale demonstrations around the world, with the Black Lives Matter ${ }^{1}$ movement bringing police, criminal justice (and societal) racism into sharp focus (Safi 2020). In the UK, in addition to the current public debate, the practices and culture of the police in relation to ethnic minorities has come under intense scrutiny at various points over the last five decades, manifesting in civil unrest (Lewis et al. 2011; Scarman, 1981) and the investigation of procedural injustice (Macpherson, 1999). There exists a long history of strained police relations with many ethnic minority communities (Bowling and Phillips, 2002; Gilroy, 1987; Hall et al., 1978), and the historic and continued underrepresentation of ethnic minority police officers in Britain has been argued to be both symptomatic of and contributory to such tensions (Brain, 2013; Cashmore, 1991; Kinsey et al., 1986). In fact, only recently the president of the National Black Police Association suggested the underrepresentation of ethnic minority police officers:

'...hinders true police community engagement, reduces information flows, encourages distrust and a lower confidence, and reduces policing effectiveness.' (Dodd 2018).

The most recent Home Office figures show that $7 \%$ of police officers in England and Wales are from ethnic minorities, ${ }^{2}$ compared to $14 \%$ of the population (Home Office, 2019).

\footnotetext{
${ }^{1}$ The grassroots Black Lives Matter movement originated in America following the acquittal of George Zimmerman after shooting and killing 17-year-old Trayvon Martin in Florida in 2012. It has harnessed social media (particularly twitter) as a platform to shape national and international discourse on police violence and racism (Carney, 2016).

${ }^{2}$ In the UK, Black or minority ethnic (BME) or Black, Asian and minority ethnic (BAME) terminology is often used to describe people of African-Caribbean, Black British or Asian backgrounds (it was originally intended to encompass both White and non-White ethnic minorities, but is now most often used to refer to all non-White ethnic minorities). However, it has been argued that these terms homogenise people from a variety of different ethnic and cultural backgrounds and obscure the disadvantages suffered by specific groups (Okolosie et al. 2015). Further, these terms are
} 
Whilst there is some variation between constabularies, underrepresentation in more culturally diverse areas is starker still; in London, $15 \%$ of police officers are from ethnic minorities, compared to over $40 \%$ of the population. Underrepresentation also occurs across different ethnic minority groups. For example, although the London Metropolitan Police Service (MPS) employs nearly 70\% of all Black officers in England and Wales, they are still underrepresented in the capital (3.5\% of officers compared to $13.3 \%$ of Londoners). It is likely that underrepresentation is stronger still within these broad ethnic categories, but a lack of granularity in the Home Office dataset makes it impossible to make any more detailed comparisons. ${ }^{3}$

The importance of 'community accountability' - ensuring police organisations are responsive to the communities they serve - has been highlighted at regular intervals over the last few decades. In the UK, the issue of ethnic representation has been central to these discussions, and several key reports such as Scarman (1981), and later Macpherson (1999), have underlined its importance in terms of both symbolic and pragmatic outcomes (Bullock et al., 2017). The recruitment of ethnic minority officers has slowly been increasing in recent years - mostly due to an increase in Asian and mixed ethnicity officers (Hales, 2020) - but representative parity remains a long way off. Recent analysis indicates that, based on current trends, the police service in England and Wales will not be representative of today's share of ethnic minorities until 2052 (Pósch, 2018). According to the MPS's own calculations, at

not generally used internationally; for example, contemporary US usage includes 'African American', 'Afro-American', 'Hispanic', 'Latino/Latina', and 'Chinese American' (Bullock et al. 2017). To reflect the differences in terminology across countries - and concerns with the usage of the acronyms BME and BAME - in this paper we have chosen to use the term 'ethnic minorities' and, where possible, we break this down further to highlight the differential experiences of specific ethnic and cultural groups.

${ }^{3}$ Interestingly, there is slightly better ethnic minority representation amongst both police staff and Police Community Support Officers (PCSOs), although police cuts have seen diversity levels decrease in recent years (Hales 2020). 
current recruitment rates, officers will not be ethnically representative of London's population for another one hundred years (Dodd, 2019).

The general acceptance that increased representativeness is morally and symbolically important belies a thin evidence base. There have been few empirical studies focusing on whether officer ethnicity influences how citizens perceive and respond to police, and little exploration into how citizens from different ethnic or cultural backgrounds perceive officers of similar or different ethnic appearance to themselves. This paper draws on the interconnected theories of representative bureaucracy, social identity and procedural justice to begin the process of addressing this knowledge gap. To our knowledge, this is the first attempt in a UK context to explore the effect of officer ethnic appearance on citizen perceptions, and consider the interaction between citizen and officer ethnicity.

This paper proceeds in five main parts. First, we discuss the empirical evidence base relating to ethnic minority perceptions of the police, and outline a range of factors which may affect such perceptions. With these in mind, in part 2 we draw on theories of representative bureaucracy, procedural justice and social identity and explore the limited and mixed empirical evidence relating to the effectiveness of increased ethnic representation. Data and methods, results and discussion are then presented, before concluding with the wider policy implications of our findings.

\section{Ethnic Minority Perceptions of the Police}

Public feelings about the police are of course influenced by a variety of factors. The ethnic characteristics of communities (and the officers that police them) has generated a significant body of research in this context, although findings are mixed and generally US-centric. In America, the tendency for African Americans to be less trusting and supportive of the police than Whites/Caucasians has been well established for decades (see Decker 1981, Webb and 
Marshall 1995 for reviews). Although the evidence base is far less developed, Hispanic/Latinx perceptions of the police tend to occupy a middle ground, generally being less positive than Whites but more positive than African-Americans (Schuck et al., 2008; Skogan, 2006; $\mathrm{Wu}, 2014)$. To explain variations in public perceptions of police amongst ethnic minorities, research has focused predominantly on the salience of either lived or vicarious experiences, and the particular historical antecedents within which these are situated.

In the UK, the tensions within ethnic minority police-public interactions have been vividly dissected from a sociological perspective through the output of the 'Birmingham School' in the 1970s and 80s (Gilroy, 1987; Hall et al., 1978). There is also a strong evidence base in the UK demonstrating that some ethnic minority communities consistently report lower levels of confidence in and satisfaction with the police than Whites (Bradford et al., 2017; ONS, 2019). Such findings have been common since the first policing confidence surveys were carried out in the wake of the riots of the early 1980s; for example, respondents of 'West Indian' heritage interviewed for the first Police and People highlighted concerns around being stopped without good reason (Smith, 1983; Smith and Gray, 1985). Nearly forty years on, and research in the UK indicates that people of Black Caribbean, and 'mixed' heritage, in particular, have low levels of trust and confidence, highlighting continuing issues of public confidence amongst some ethnic groups (ONS, 2019). The reasons for these disparities are multiple and complex, linking in part to both lived and vicarious experiences and set within a historical context of well documented biased or discriminatory practices which, in turn, affect inclusion and engagement (Keith 1993, Bowling and Phillips 2002; Bradford 2017).

Nevertheless, in the UK, not all ethnic minorities view the police in a negative light. For instance, people from Bangladeshi and Indian backgrounds tend to have more favourable 
views of the police than their White counterparts (ONS, 2019). This implies that the subjective perception of the police is not necessarily more negative among all ethnic minorities, despite Black British respondents having a more negative view of the police on average.

\section{Representative Bureaucracy / Community Accountability Theory}

Given the history described above it is unsurprising that policy makers have instigated initiatives designed to ensure police organisations are more representative of the communities they serve (Bullock et al., 2017). The theory of representative bureaucracy - also referred to as 'community accountability' - has been central to such efforts. Emerging from the field of public administration, representative bureaucracy theory argues that bureaucratic organisations such as the police will be most beneficial to the communities they serve if they are representative of the citizens in that community, and particularly of underrepresented groups (Mosher, 1968; Saltzstein, 1979; Trochmann and Gover, 2016). It is expected that when administrators (in this case, the police) share similar values to the citizens they serve, they will be seen as more responsive in their policies and interactions (Hong, 2016; Riccucci et al., 2014). Further, it has been argued the social environment in which administrators reside shapes their attitudes, and that their lived experience as ethnic minorities will generate an approach more sympathetic to the minority groups they police (Selden, 1997; Trochmann and Gover, 2016).

This literature distinguishes between passive, active and symbolic representation. Active representation relates to how representation shapes policy through purposeful decision making on behalf of a group (Mosher, 1982). Passive representation rests solely on whether bureaucrats share the same demographics as the community they serve, making it much easier to test empirically (Shjarback et al., 2017). Lastly, the symbolic power of a more 
representative police service has been put forward as key to gaining legitimacy, with a better understanding of local cultural issues enhancing communication, engagement and conflict resolution, and making minority officers better placed to facilitate trust (Bradford et al., 2014).

Empirical evidence of the impact of ethnic minority representation in policing is limited and findings are mixed. Several studies have examined the impact of ethnic minority representation on citizen complaints. For example, using aggregate UK police force data between 2000 and 2010 - a period in which ethnic minority representation in the police in England and Wales increased through government imposed targets (Home Office, 1999) Hong (2016) found a significant inverse association between the proportion of ethnic minority officers and the number of substantiated complaints, particularly for Black citizens. ${ }^{4}$ However, local residents tended to be less satisfied with the services ethnic minority officers provided. Smith and Holmes (2003) explored police brutality complaints in the US, and found that, for Hispanic populations, a more representative police force (i.e. where the proportion of Hispanic officers more closely matched the proportion of Hispanics in the general population) resulted in fewer complaints; however, the ratio of Black officers to citizens had no effect on the incidence of complaints. The authors argue that environmental conditions may have a more pronounced impact on citizen complaints, a suggestion echoed by other research showing that community context is more important than ethnic representation in explaining variation in complaints against police (e.g. Hickman and Piquero 2009, Trochmann and Gover 2016).

Studies that use racial profiling by police as the outcome measure generate similarly mixed results. For example, Hong (2017) explored the effect of increased ethnic minority

\footnotetext{
${ }^{4}$ Although suggestive of the benefits of representative democracy, the sheer number of factors uncontrolled for in this study means findings should be treated with caution.
} 
representation on racial profiling during stop and search and found that representative bureaucracy reduced police use of racial profiling. However, his findings are limited by the use of aggregate level data, limited controls and lack of data on changing local organisational directives. Other research using individual-level data has found the reverse relationship, with increased ethnic minority representation generating a greater incidence of racial profiling during motor vehicle stops (Wilkins and Williams 2008). The authors attributed this finding to organisational socialisation, whereby Black officers feel pressure to fit in or appear unbiased (see also Cashmore 1991, 2002, Barlow and Barlow 2000, Weitzer 2000). A recent systematic review exploring the effect of police diversity on arrest rates, crime rates and public satisfaction identified only eleven studies with sufficiently robust methodologies (Bullock et al. 2017). All of the studies were conducted in the US, and some were several decades old (e.g. Skogan 1976, Lovrich and Steel 1983). The review found that although it was not possible to conclude that increased ethnic minority representation has beneficial effects, it did not seem to worsen arrest or crime rates or negatively influence public satisfaction with the police.

Some studies have however suggested a link between workforce diversity and police effectiveness (or at least crime rates) Using force specific targets for recruiting ethnic minority officers between 1999-2009, Hong (2016) estimated the impact of representative bureaucracy on crime rates in England and Wales. He found a 10 per cent increase in the share of ethnic minority officers was associated with between a 1.4 and 3.8 per cent decrease in Home Office recorded crime. A recent study by Chenane and Wright (2018) examined the role of ethnic minority officer representation on violent crime in immigrant neighbourhoods in the US. Drawing on data from 89 cities and 8,980 neighbourhoods and employing multilevel modelling, they found that immigrant concentration was associated with lower robbery 
and homicide rates, and that this negative relationship was strengthened by city level African American and Hispanic officer representation.

One of the studies included in Bullock and colleagues' (2017) systematic review used qualitative data from in-depth interviews with residents of a neighbourhood with a majority Black police force and population (Brunson and Gau 2015). The authors concluded that having a representative police force will not necessarily guarantee positive interactions and satisfaction. Importantly, their findings suggested the ecology of the local area - and specifically the structural deficits experienced - were far more likely to impact on perceptions of police than the ethnicity of the officer. Similar results were found by Weitzer (2000b) who suggested that social class may be a factor in the impact of representative bureaucracy: interviewees in his study who were from middle class Black neighbourhoods had no preference for the ethnicity of the officers that policed them.

Further, several studies have found that organisational culture overrides any impact of minority representation, be that female (Schuck and Rabe-Hemp, 2016) or ethnic minority officers (Wilkins and Williams, 2008). This finding is in line with the 'blue all over' thesis: that 'cop culture' supersedes racial differences, minimising differences in treatment and thus potentially engendering minimal change (Decker and Smith, 1980; Moskos, 2008; Weitzer, 2000b). It has also been found that ethnic minority police officers may be at risk of more negative outcomes. For example, Weitzer (2000a) found that Black citizens often harboured more negative attitudes to Black officers, and Barrick et al. (2014) found that assault levels on police increased as the representation ratio increased. However, other research has found no association between ethnic minority representation and assaults on police, either at aggregate level or within Black, Asian and Hispanic ethnic groups (e.g. Ozkan et al. 2016). In sum, empirical evidence of the benefits of representative bureaucracy within policing is mixed; however, it is clear that shared ethnicity alone cannot guarantee positive outcomes. 


\section{The relevance of Procedural Justice and Social Identity Theory}

A key facet of representative bureaucracy theory is that increased diversity is expected to enhance the legitimacy of the police within the community they serve, improving the quality of police-public interactions. Here, elements of procedural justice theory are instructive in understanding how this process might occur. Specifically, the group-engagement model of procedural justice posits that fair treatment by authorities is important because it represents inclusion and status within the group the authority represents (Tyler and Blader 2003; Blader and Tyler 2009). Fair treatment by the police can foster a sense of belonging (cognitive component) and increase the worth people place on the group the police represent (evaluative component). Because social groups are important to most people, feelings of inclusion and value will increase the likelihood that they see the group itself to be legitimate, and support its authority appropriately (Bradford, 2014). Linked closely to this concept is social identity theory, which at its most basic argues that individuals are more likely to favour members of their ingroup over members of their outgroup (Hogg, 2006). In order to identify their 'ingroup' in the fleeting moments that characterise many people's experience of, for example, policing, they will draw on accessible social categorisations, such as gender or ethnicity. And, importantly, when citizens feel connected to the social group the police and other authority figures represent, they are more likely to view them positively - as trustworthy, legitimacy authorities - and are more likely to comply and cooperate with the structures and rules the institution represents (Tyler and Huo 2002, Turner and Reynolds 2010, Bradford 2014; Jackson and Pósch 2020).

In the current study we capture this process by asking respondents to rate their affective (emotional) response to images of police officers and others. We do this for two reasons. First, we attempt in the experiment described below to replicate the way many people experience policing - as a series of short, dislocated encounters wherein they may see 
officers briefly, maybe exchanging a few words with them, witnessing them interacting with a third party, or being directed by them at a sporting event or at the scene of an accident. Under such conditions what seems most relevant is to capture people's 'gut responses' to police - whether they feel warm or cold towards them, and feel that they are trustworthy or threatening.

Second, however, is precisely the close link between (positive) affect, trust and indeed other key concepts in procedural justice theory, such as legitimacy. Research over many years has stressed the extent to which affect and trust are mutually constitutive. Most importantly in the current context, affective attachment to ingroup or indeed outgroup members is thought to generate trust. Williams (2001) suggests that people use their feelings toward another as information when making judgements about that person's trustworthiness (see also (Slovic et al. 2002, 2004), and that positive affect also motivates trust because we wish to maintain relationships with those to whom we feel emotionally close. As Midden and Huijts argue (2009, p. 744), 'the concept of trust refers to a feeling that another person is caring, morally good, and has positive intentions toward the person who trusts' - feelings that seem very likely to flow from one's affective response to them.

Relatively few studies have tested theories of trust, procedural justice and social identity theories in relation to police and citizen ethnicity. Examining the effect of shared ethnicity with broadly defined 'legal authorities' (including the police), Tyler and Huo (2002) found that White citizens were significantly more likely to accept decisions from White authorities but that there was no difference in Black or Hispanic willingness to accept decisions between White or non-White authorities. Theobald and Haider-Markel (2009) using individual-level US survey data - found that Black respondents were more likely to perceive police actions as legitimate if there were Black officers present; this pattern held for non-minorities as well, with Whites more likely to perceive police actions as legitimate if 
White officers were present. Recent research has replicated these findings in a court setting, showing that Black or Hispanic offenders who shared their race/ethnicity with the prosecutor, perceived their treatment to be significantly more just (Baker, 2017; Baker et al., 2015).

There is much to suggest, therefore, that the ethnic appearance of police officers is an important factor in understanding police-citizen relationships and trust in police among ethnic minorities. However, there are a number of limitations of previous research and very little research from a UK context. This study aims to begin the process of addressing this knowledge gap.

\section{The Current Study}

The study design is based on Simpson's (2017) Police Officer Perception Project (POPP) methodology. Simpson presented people with a series of images of police officers, manipulating attire (whether the officer was in uniform or civilian clothing) and patrol method (on foot, bicycle or car). Simpson found that officers were viewed more favourably when pictured in uniform and on bicycle and/or foot. We employ a similar methodology to explore the effects of officer and respondent ethnicity. Participants in our study were shown a series of images of police officers in which we manipulated the officer's ethnic appearance (i.e. White, Black or Asian). Based on the evidence presented above, we ask, does varying the ethnic appearance of police officers affect how people respond to them? Specifically, we propose the following hypotheses:

H1: White and Asian participants will respond more positively to police officers than Black participants.

H2: Participants will respond more positively to police officers of the same ethnic appearance as themselves, compared to police officers of different ethnic appearance. 


\section{Data and Methods}

\section{Participants}

Participants for this study were recruited using the online platform Prolific Academic between 15-17 April 2019. Prolific is similar to other crowdsourcing platforms such as Mechanical Turk but has a larger, more diverse pool of UK participants. All participants were resident in England, Wales or Scotland and respondents were selected based on their selfdefined ethnicity, at a ratio of $60 \%$ White, $20 \%$ Asian and 20\% Black. After excluding people who failed the attention and validation checks $(n=56$, see below), the final sample consisted of 260 respondents. Across the different conditions, similar people were excluded, and balance tests carried out indicated that, on average, respondents in each condition remained similar across observable characteristics. Participants were paid a nominal fee for taking part in the study ( $£ 1.20$ for an estimated completion time of 10 minutes). Key demographic characteristics are presented in Table 1.

[Table 1 about here]

Just under two thirds of respondents were female, and exactly one-third were aged under 35 years. Of the valid responses, $18 \%$ identified as Asian or Asian British, with nearly half of these identifying as Indian (47\%), 23\% as Pakistani, $11 \%$ as Bangladeshi, and the remaining $19 \%$ as 'any other Asian background'. Black or Black British respondents $(17 \%$ of the sample) predominantly classified themselves as African (56\%) or Caribbean (37\%) of origin. White participants overwhelmingly identified as White British (82\%), with the remainder identifying as White Irish or 'any other White background'. Over three quarters of participants were born in the UK (78\%). Around one third of participants resided in the South East (either Greater London (18\%) or the Home Counties, (17\%)), 8\% were from Scotland, and $3 \%$ from Wales. 


\section{Method}

We used Qualtrics to build the experiment. After reading an information sheet and consenting to the study, participants were presented with a set of six different images of police officers. Participants were randomly assigned to one of three ethnic appearance conditions and saw images of officers who appeared either Asian, Black, or White. ${ }^{5}$ This random assignment meant that, in each condition, participants were on average similar across all observable and unobservable characteristics. The images used were stock photographs of police officers in the UK. Matching was undertaken across the three ethnic appearance conditions to identify similar images in terms of gender, stance, expression, facial features, background and framing. In each condition, two of the six images were of female police officers, which is broadly representative of the proportion of women in UK policing.

Matching both within and across ethnic appearance is fraught with methodological difficulties. Firstly, there were a limited number of stock images of ethnic minority police officers in the UK, presumably due to the very underrepresentation which forms the basis of this study. Secondly, although participants could be selected based on their self-classified ethnicities, image selection necessitated a subjective interpretation of ethnic appearance. Ethnic appearance can be seen on a subjective spectrum, and variance even between 'simple' ethnic categories of White, Black and Asian (let alone within them) is virtually infinite; subtle distinguishing features may lead one person to deduce a different ethnic categorisation than another. We tried to minimise ambiguity as much as possible and used skin colour as the primary determinant of ethnic categorisation. Finally, a pilot study was carried out on Prolific Academic with the aim to assure that the matched pictures were perceived to be more similar

\footnotetext{
${ }^{5}$ An aggregation of ethnic appearance categories was deemed necessary in order to facilitate the analytical approach; we acknowledge the drawbacks of such broad categorisation against a reality that is fluid and highly contextualised; this is discussed further in the limitations section below.
} 
to each other than to the pictures in other sets. The results of this pilot indicated a similarity between matched pictures, suggesting that, comparing images between different sets, ethnic appearance was the primary distinguishing feature (results are available from the authors upon request).

Participants rated each of the six images on five variables measuring their immediate affective response to seeing the image (see measures section below). Instructions and layout were designed to elicit a quick response. Following each image and set of affective responses, the next image appeared on the screen and the process was repeated until the participants had rated all six images across all five response variables: a total of 30 sequential ratings. Both the images and the order by which participants rated the affective responses were randomised.

Following the main task, participants were presented with a validation check. ${ }^{6}$ Participants were then asked a series of questions relating to their perceptions of the police in their local area. ${ }^{7}$ Finally, demographic information was collected, and participants were given a full debrief.

\section{Constructs and measures}

\section{Affective responses to the images}

Participants rated each image on five variables presented on an 11-point semantic differential scale (adapted from Yesberg and Bradford 2019) from: (1) not approachable to approachable,

\footnotetext{
${ }^{6}$ Participants were asked: 'How many images showed people of White ethnic appearance?' via multiple choice answer format.

${ }^{7}$ These measures included: procedural justice, bounded authority, sense of power, legitimacy, cooperation, community engagement, relational identification, and identity. Because these measures are not relevant to the current hypotheses, we do not report on them in this paper. However, attention checks were included within the measures and participants were excluded from analysis in this paper for failing them.
} 
(2) not aggressive to aggressive, (3) not friendly to friendly, (4) not respectful to respectful, and (5) not trustworthy to trustworthy. These comprise the dependent variables for this study.

\section{Analytical approach}

Each rating of each image was treated as a distinct observation, with these observations nested within respondents. This nested structure makes it likely that the independence assumption of the general linear regression analysis would be violated, hence, an alternative model-specification is required where this nested structure is considered. One way of addressing this issue is by partitioning the overall variance to within- and between-person components. Therefore, to test our hypotheses, a series of multi-level linear regression models (i.e., random intercept models) were estimated using STATA 15. We estimated separate models for each of the five dependent variables (i.e. the degree to which people rated the officer in the image as approachable, aggressive, friendly, respectful and trustworthy). Variables indicating the ethnic appearance of the officer on the pictures $(1=\mathrm{Black}, 2=$ White, $3=$ Asian $)$ and the ethnicity of the respondents (1=Black, $2=$ White, $3=$ Asian $)$ were entered into the models as predictors, then interactions were tested between them.

Within-individual variance is the part of the overall variance that is attributable to the individual responding to the given questions. Conversely, between-individual variation is attributable to the differences between the individuals. The intraclass correlation coefficient quantifies the variation that belongs to the differences across individuals. This varied depending on the outcome variable from small (friendly $=0.10$; approachable $=.14$ ) to moderate (aggression $=.026$; respect $=0.28$; trust $=0.32$ ) in size. Even in the case of the largest ICC, the majority of the variation (.68-.90) could be attributed to differences across the individuals. 
Although, in case of random intercept models the homoskedasticity and normality of the residuals are often assumed, this is, in fact, not required for the estimation of the regression coefficients. A more stringent assumption, however, is that the individual-level (withinperson) residuals are uncorrelated with any of the covariates in the model. Due to the random assignment of individuals to each condition, this holds true by design (Clarke et al. 2016).

\section{Results}

Table 2 presents the results of the models with officer and respondent ethnicity entered as predictors. First, looking at the effect of officer ethnic appearance, we found that compared to Black officers, White officers were rated significantly less approachable $(\beta=-.67)$, less friendly $(\beta=-.61)$, less respectful $(\beta=-.42)$, less trustworthy $(\beta=-.57)$ and more aggressive $(\beta=1.04)$. Similarly, compared to Black officers, Asian officers were rated significantly less approachable $(\beta=-.90)$, less friendly $(\beta=-.90)$, less respectful $(\beta=-.81)$, less trustworthy $(\beta$ $=-.85)$ and more aggressive $(\beta=.97)$. Overall, Asian officers were rated as the least approachable, friendly, respectful and trustworthy, whereas White officers were rated as the most aggressive. ${ }^{8}$ It is notable that the treatment had the most profound impact on the perception of aggression, where the officer being White or Asian compared to Black had a very similar effect size. In contrast, the effect sizes of the positive characteristics showed a similar pattern, with the Asian treatment condition having stronger and the White condition having a weaker negative effect compared to the Black condition.

[Table 2 about here]

\footnotetext{
${ }^{8}$ Of note, whilst not displayed here, we also gathered data on perceptions of civilians of different ethnic appearance. Findings showed that Asian civilians were rated the most positively and White civilians were rated the least positively; Black civilians occupied the middle ground.
} 
Second, looking at the effect of respondent ethnicity, compared to Black respondents, White respondents were significantly more likely to rate police officers as respectful $(\beta=.53)$ and trustworthy $(\beta=.58)$, and significantly less likely to rate them as aggressive $(\beta=-.57)$. There were no significant differences between Black and Asian respondents' affective responses toward police. Overall, and based on the comparison of the effect sizes, ethnicity had a smaller influence compared to the experimental treatment.

We estimated the $\mathrm{R}^{2}$ coefficients for each of our models to quantify the variation explained overall and between the participants. Based on these estimates, differences in the perception of trustworthiness were best explained, followed by approachability, respectfulness, aggressivity, and finally friendliness.

Lastly, we explored the interaction between respondent ethnicity and officer ethnic appearance. Results are presented in Table 3 and show that, compared to Black respondents, both White $(\beta=1.17)$ and Asian $(\beta=1.57)$ respondents were significantly more likely to rate images of White officers as approachable. In other words, Black respondents were significantly less likely to view White officers as approachable. This interaction is highlighted in Figure 1, which plots the predicted probability of rating an officer approachable by respondent ethnicity and officer ethnic appearance. The gap between Black respondents' ratings of White officers is stark, with little other meaningful differences in ratings between respondent ethnicities. 
Figure 1. Interaction between respondent ethnicity and officer ethnic appearance on ratings of approachability

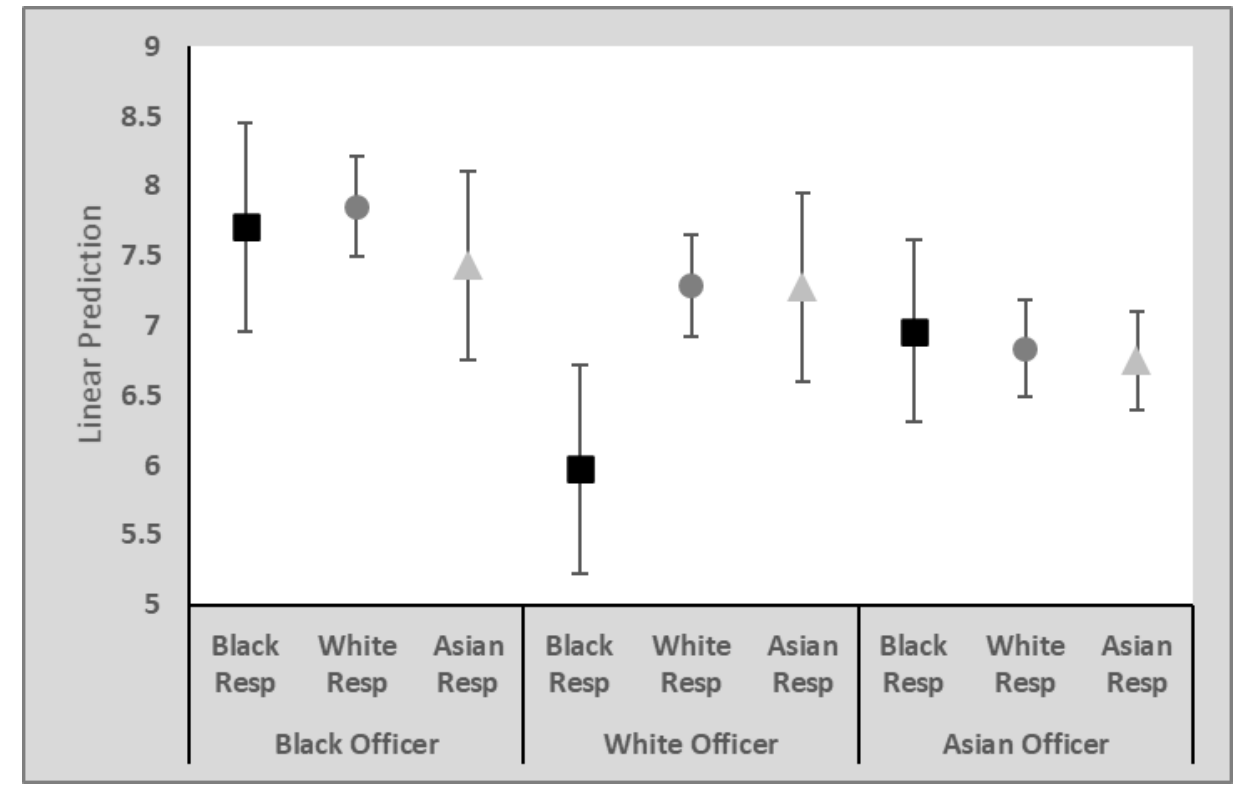

This same pattern was repeated for ratings of friendliness: compared to Black respondents, both White $(\beta=1.16)$ and Asian $(\beta=1.52)$ respondents were significantly more likely to rate White officers as friendly. For ratings of respectfulness, only the interaction for Asian respondents was significant $(\beta=1.30)$, and for trustworthiness neither interaction was significant, although the pattern was similar (with Black respondents overall rating White officers less favourably).

The only affective response that behaved differently was aggression. Figure 2 demonstrates this interaction. Compared to Black respondents, White respondents were significantly less likely to rate White officers as aggressive $(\beta=-1.41)$, but there was no difference between Black and Asian respondents. Asian respondents were slightly more likely to rate Black officers aggressive, but this interaction was not significant. 
Figure 2. Interaction between respondent ethnicity and officer ethnic appearance on ratings of aggressiveness

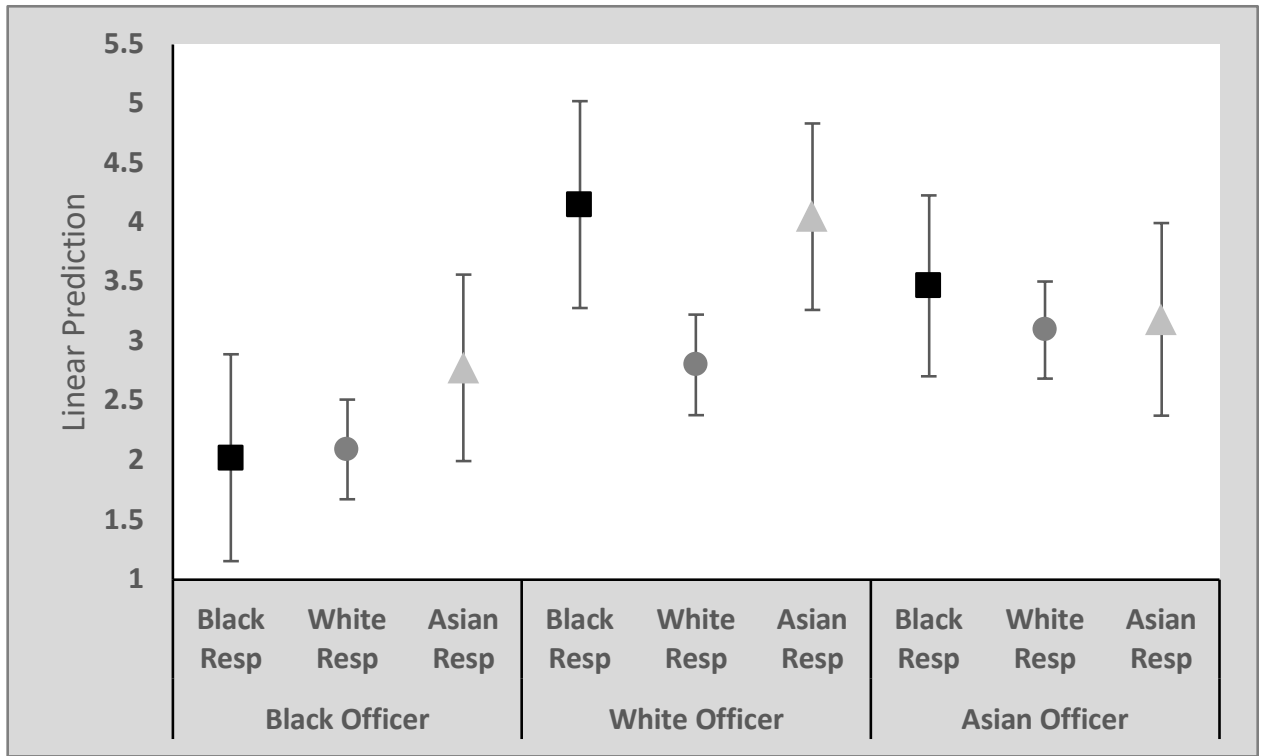

Importantly, when including the interaction term in the models, the main effects of officer ethnic appearance largely remained significant (with White and Asian officers perceived less favourably than Black officers). However, the main effects of participant ethnicity (i.e. that White participants had more favourable perceptions of officers than Black participants) were rendered non-significant. This finding suggests that all the effect of participant ethnicity can be attributed to the interaction. The small gains in the explained variation of each model (demonstrated by the increased $R^{2} s$ ) provides further justification of adding the interactions to the models. Overall, then, results seem to show that Black respondents consistently rate images of White police officers less favourably than White or Asian respondents (although note the exception for Asian respondents' ratings of aggressiveness).

\section{Discussion}

This study explored whether ethnic appearance affected how people responded to police officers, and explored the interaction between officer and respondent ethnicity. 
Analysis demonstrated, first, that Black officers were consistently rated more positively than both White and Asian officers. One plausible - although perhaps overly optimistic interpretation of this finding may be that people have an awareness of the barriers Black people must overcome in order to become police officers, and thus tend to view them as exceptional for overcoming these barriers (and rate them accordingly). Of course, social desirability bias could also be playing a role - participants may have intuited that they were 'meant' to rate minority officers more favourably. However, people of Asian ethnic background arguably face similar hurdles in becoming police officers, and our findings showed that Asian police officers were, on the whole, rated less positively than both White and Black officers. It could be that the barriers Asian individuals face are less discussed in the public or academic domain, or that people consider discrimination against Asian people to be less of a problem than discrimination against Black people (or both).

Our first hypothesis was that Black respondents would have more negative affective responses toward police. We found, at least compared to White respondents, this was indeed the case across three outcomes: Black respondents rated images of police as less respectful, less trustworthy and more aggressive. These findings are in line with previous research from both the UK and the US which have noted the consistently poorer perceptions of police from ethnic minorities; particularly, in the UK, from those of Black African or Caribbean descent (ONS, 2019; Peck, 2015). Our findings thus further highlight the continuing issues of trust and confidence in police among Black citizens, and underscore the need for research and policy to develop initiatives to address this confidence deficit.

Our second hypothesis was that respondents would rate police officers of similar ethnic to themselves more favourably; and, correspondingly, rate officers of different ethnic appearance to themselves less favourably. Findings here were mixed, but we did find that Black respondents had consistently more negative responses to officers of White ethnic 
appearance. We also found that White respondents were significantly less likely to rate officers of the same ethnic appearance as themselves as aggressive, compared to officers of both Black and Asian ethnic appearance. These findings resonate with social identity theory: respondents, particularly those of Black ethnicity, were more likely to (a) favour members of their ingroup and (b) view outgroup members less favourably. However, more research is needed to better understand the role of officer ethnic appearance in influencing citizens' perceptions of police. As Brunson and Gau (2015) note, there are significant dangers in making assumptions that shared ethnic appearance is a proxy for understanding and empathy - a shared ethnic background is unlikely to be sufficient to guarantee positive interactions between ethnic minority officers and citizens, or lead to improved relations (Dowler and Sparks, 2008).

In diverse societies, people often have multiple identities making it difficult for representation alone to bridge the gap between various groups (Wiley et al., 2019; Yuval, 2020). To address these difficulties, procedural justice theory highlights the importance of officer behaviour and perceptions of fair and appropriate treatment as normative identityneutral signals. This theory argues that fair and respectful treatment by the police communicates status and inclusion, making it a more effective mechanism for improving perceptions and legitimacy of the police amongst minority groups than increased minority representation alone (Bullock et al., 2017). As Bradford (2014) notes, 'the police are a highly visible representation of the state, a concrete instantiation of its (often failed) claim to protect and represent all citizens' (p.3). Individuals who do not feel either of these benefits - who do not feel protected and represented by police - are more likely to harbour negative perceptions. Furthermore, previous negative experiences with the police may supersede the positive impact of any feelings of shared identity with officers of similar ethnic appearance (Bullock et al., 2017). There is likely, that is, to be an interaction between who the police are 
and what they $d o$. This, yet again, underlines the importance of how the police treat citizens; that is, of procedural justice.

In sum, our findings offer some support for the idea that increasing the representativeness of UK policing, aside from simply being the right thing to do, will reap dividends in terms of increased public trust and better relationships between police and policed. That the most consistent findings related to Black officers and respondents is perhaps not surprising. The relationship between the police and Black communities remains fraught, and has a long 'history' that has, arguably, created deep categorical distinctions between the two groups.

To our knowledge no prior UK study has considered the basic questions we have examined here - how do people view officers of different ethnic appearances, and does this vary by their own ethnicity? It is therefore somewhat heartening to find that Black officers are viewed more positively, and unsurprising, if less heartening, to find that Black respondents view White officers less positively. The policy lesson here seems clear. If police organisations are able to increase the representativeness of their workforce this may improve relations with precisely those groups where this is most needed - because increasing the number of officers who are 'like them' will increase the chances of people from those groups interacting in a positive fashion with those officers. At the same time, at least on the evidence presented here, it seems this will have little negative effect in relation to other groups, most notably the White British majority. Increasing police diversity might, on this basis, be a 'winwin' scenario: increasing trust within marginalised groups not currently well represented in/by the police, without undermining trust among the majority group, while also addressing the ethical imperative of removing the barriers to entry faced by ethnic minority candidates (although this latter would of course be the subject of a quite different paper). 


\section{Limitations}

There are a number of limitations to this study that must be addressed. First, we acknowledge the experimental conditions under which this study took place are no substitute for a real world setting, and the situation is, in reality, far more complex than can be captured in an experimental design. We also note the limits of our materials, using stock images of police officers, and limiting our ethnic appearance categories to White, Black and South Asian. In reality, ethnic categorisation is a much more complex process and there are significant issues with attempting to collapse into categories something that is fluid and highly contextualised. The range of possible ethnic and cultural-religious backgrounds our classifications contained is likely many. Further, whilst the ethnic background of our respondents was known (through self-classification), the ethnicity of the police officers was inferred based on appearance, and this may differ from what the officers themselves, or others, perceive.

\section{Conclusion}

Although there is a general consensus that achieving a more ethnically representative police service is morally the right thing to do, there is limited empirical evidence to support the idea that this will improve policing in a more concrete sense. This study has provided some preliminary evidence that a more representative police force may lead to more positive perceptions of police, and, as a result, generate trust and legitimacy. Black respondents in our study had less positive feelings toward White officers, and tended to favour officers of their own ethnic appearance. Given the historical low levels of trust and confidence in police within many Black communities, our findings suggest that having a police service that is more reflective of their ethnicity may increase feelings of inclusion, and improve overall relations with police among this ethnic group. 
Our findings also showed that Black officers were perceived more favourably across respondents of all ethnicities, and there was little to suggest Black officers elicited negative reactions from White or Asian respondents. These findings suggest that, even if enhanced representation fails to increase trust and confidence among Black citizens, it is unlikely to do any harm. Of course, this study is just a first step to unpicking the complex relationship between officer and citizen ethnicity and it is hampered by a number of limitations, notwithstanding the experimental conditions under which it took place. As a final thought, we would stress that increased ethnic minority representation will not, in and of itself, change an organisation's policies, which in themselves may be discriminatory and unfair. Any attempts to increase ethnic representation within policing should be made within the wider context of structural and organisational changes, as recent protests vividly emphasise. 


\section{References}

Baker T (2017) Exploring the relationship of shared race/ethnicity with court actors, perceptions of court procedural justice, and obligation to obey among male offenders. Race and Justice 7(1): 87-102.

Baker T, Pickett JT, Amin DM, et al. (2015) Shared Race/Ethnicity, Court Procedural Justice, and Self-Regulating Beliefs: A Study of Female Offenders. Law and Society Review 49(2): 433-466.

Barlow DE and Barlow MH (2000) Police in a Multicultural Society: An American Story. Prospect Heights, IL: Waveland Press.

Barrick K, Hickman MJ and Strom KJ (2014) Representative policing and violence towards police. Policing: A Journal of Policy and Practice 8(2): 193-204.

Bowling B and Phillips C (2002) Racism, Crime, and Justice. Harlow: Longman.

Bradford B (2014) Policing and social identity: procedural justice, inclusion and cooperation between police and public. Policing and Society 24(1): 22-43.

Bradford B, Murphy K and Jackson J (2014) Officers as mirrors. British Journal of Criminology 54(4): 527-550.

Bradford B, Sargeant E, Murphy K, et al. (2017) A leap of faith? Trust in the police among immigrants in England and Wales. British Journal of Criminology 57(2): 381-401.

Brain T (2013) A Future for Policing in England and Wales. Oxford: Oxford University Press.

Brunson RK and Gau JM (2015) Officer Race Versus Macro-Level Context: A Test of Competing Hypotheses About Black Citizens' Experiences With and Perceptions of Black Police Officers. Crime and Delinquency 61(2): 213-242. 
Bullock K, Fielding J, Fielding N, et al. (2017) What Works: Crime Reduction Systematic Review Series: No 12. The Police Service, Diversity and Organisational Outcomes: A Report of a Systematic review. Available at:

https://whatworks.college.police.uk/Research/Systematic_Review_Series/Documents/Di versity_SR.pdf.

Carney N (2016) All Lives Matter, but so Does Race: Black Lives Matter and the Evolving Role of Social Media. Humanity \& Society 40(2): 180-199

Cashmore E (1991) Black Cops Inc. In: Cashmore E and McLaughlin E (eds) Out of Order? Policing Black People. New York: Routledge, pp. 87-108.

Cashmore E (2002) Behind the window dressing: ethnic minority police perspectives on cultural diversity. Journal of ethnic and migration studies 28(2): 327-341.

Chenane JL and Wright EM (2018) The Role of Police Officer Race/Ethnicity on Crime Rates in Immigrant Communities. Race and Justice.

Clarke P, Crawford C, Steele F and Vignoles A (2015) Revisiting fixed- and random-effects models: some considerations for policy-relevant education research. Education Economics 23(3) 259-277.

Decker SH (1981) Citizen attitudes toward the police: A review of past findings and suggestions for future policy. Journal of Police Science and Administration 9(1): 80-87.

Decker SH and Smith RL (1980) Police minority recruitment: A note on its effectiveness in improving black evaluations of the police. Journal of Criminal Justice 8(6): 387-393.

Dodd V (2018) 'II's nowhere near good enough': broken promises on police diversity', The Guardian, 5 December, Available at: https://www.theguardian.com/uknews/2018/dec/05/its-nowhere-near-good-enough-broken-promises-on-police-diversity. 
(Accessed: 2 March 2019)

Dodd V (2019) 'Met disproportionately white for another 100 years - police leaders', The Guardian, 19 Feburary, Available at: https://www.theguardian.com/uknews/2019/feb/19/met-police-disproportionately-white-for-another-100-years.

(Accessed: 19 February 2019)

Dowler K and Sparks R (2008) Victimization, contact with police, and neighbor- hood conditions: Reconsidering African American and Hispanic attitudes toward the police. Police Practice and Research 9: 395-415.

Gilroy P (1987) There Ain't No Black in the Union. London: Routledge.

Hales G (2020) A diversity uplift? Police workforce gender and ethnicity trends from 2007 to 2018 and prospects for the future. London.

Hall S, Critcher C, Clarke J, et al. (1978) Policing the Crisis: Mugging, the State, and Law and Order. London: Macmillan.

Hickman MJ and Piquero AR (2009) Organizational, administrative, and environmental correlates of complaints about police use of force: Does minority representation matter? Crime \& Delinquency 55(1): 3-27.

Hogg MA (2006) Social identity theory. In: Burke PJ (ed.) Contemporary Social Psychological Theories. Palo Alto, CA: Stanford University Press, pp. 111-136.

Home Office (1999) Dismantling Barriers to Reflect the Community We Serve: The Recruitment, Retention, and Progression of Ethnic Minority Officers: Targets. London.

Home Office (2019) Police workforce, England and Wales, 31 March 2019. Available at: https://assets.publishing.service.gov.uk/government/uploads/system/uploads/attachment _data/file/831726/police-workforce-mar19-hosb1119.pdf. 
Hong S (2016) Representative bureaucracy, organizational integrity, and citizen coproduction: Does an increase in police ethnic representativeness reduce crime? Journal of Policy Analysis and Management 35(1), 11-33.

Hong S (2016) Does Increasing Ethnic Representativeness Reduce Police Misconduct? Public Administration Review 77(2): 195-205.

Hong S (2017) Black in blue: Racial profiling and representative bureaucracy in policing revisited. Journal of Public Administration Research and Theory 27(4): 547-561.

Jackson J and Pósch K (2020) Methodological Directions of Reserch into Legitimacy and Legal Authority: A Focus on Causal Mechanisms. In: Social Psychology and Justice. Wiley, pp. 181-212.

Keith M (1993) Race, Riots and Policing: Lore and Disorder in a Multi-Racist Society. London: UCL Press.

Kinsey R, Lea J and Young J (1986) Losing the Fight against Crime. London: Blackwell.

Lewis, P, Newburn, T, Taylor, M, Mcgillivray, C, Greenhill, A, Frayman, H and Proctor, R (2011) Reading the riots: investigating England's summer of disorder. Reading the riots. The London School of Economics and Political Science and The Guardian, London, UK.

Lovrich NP and Steel BS (1983) Affirmative Action and productivity in Law Enforcement Agencies. Review of Public Service Administration 4(1): 55-66.

Macpherson W (1999) The Stephen Lawrence Inquiry. London.

Midden, C. J. and Huijts, N., 2009. The role of trust in the affective evaluation of novel risks: The case of CO2 storage. Risk analysis, 29(5), 743-751. 
Mosher FC (1968) Democracy and The Public Service. Oxford: Oxford University Press.

Mosher FC (1982) Democracy and the Public Service. New York: Oxford University Press.

Moskos P (2008) Cop in the Hood: My Year Policing Baltimore's Eastern District.

Princeton, New Jersey: Princeton University Press. Okolosie, L, Harker, J, Green, L and

Dabiri, E (2015) 'Is it time to ditch the term 'black, Asian and minority ethnic'

(BAME)?' The Guardian, 22 May, Available at:

https://www.theguardian.com/commentisfree/2015/may/22/black-asian-minority-ethnic-

bame-bme-trevor-phillips-racial-minorities (Accessed: 12 June 2020).

ONS (2019) Confidence in the local police. Available at: https://www.ethnicity-facts-

figures.service.gov.uk/crime-justice-and-the-law/policing/confidence-in-the-localpolice/latest.

Ozkan T, Worrall JL and Piquero AR (2016) Does Minority Representation in Police Agencies Reduce Assaults on the Police? American Journal of Criminal Justice 41(3). American Journal of Criminal Justice: 402-423.

Peck JH (2015) State-of-the-art review minority perceptions of the police: A state-of-the-art review. Policing 38(1): 173-203.

Pósch K (2018) Police diversity and \#biasinbritain 1. Available at: https://krisztianposch.net/police-diversity-and-biasinbritain-1/.

Riccucci NM, Van Ryzin GG and Lavena CF (2014) Representative bureaucracy in policing: Does it increase perceived legitimacy? Journal of Public Administration Research and Theory 24(3): 537-551.

Safi, M (2020) 'George Floyd killing triggers wave of activism around the world', The Guardian, 9 June, Available at: https://www.theguardian.com/us- 
news/2020/jun/09/george-floyd-killing-triggers-wave-of-activism-around-the-world.

(Accessed: 9 June 2020)

Saltzstein G (1979) Representative Bureaucracy and Bureacratic Responsibility: Problems and Prospects. Administration \& Society 10(4): 465-475.

Scarman LG (1981) The Brixton disorders 10-12 April 1981: report of an inquiry (Vol. 8427).

Schuck AM and Rabe-Hemp C (2016) Citizen complaints and gender diversity in police organisations. Policing and Society 26(8). Routledge: 859-874.

Schuck AM, Rosenbaum DP and Hawkins DF (2008) The influence of race/ethnicity, social class, and neighborhood context on residents' attitudes toward the police. Police Quarterly 11(4): 496-519.

Selden SC (1997) Representative bureaucracy: examining the linkage between passive and active representation in the farmers home administration. The American Review of Public Administration 27(1): 22-42.

Shjarback J, Decker S, Rojek JJ, et al. (2017) Minority representation in policing and racial profiling: A test of representative bureaucracy vs community context. Policing 40(4): $748-767$.

Simpson R (2017) The Police Officer Perception Project (POPP): An experimental evaluation of factors that impact perceptions of the police. Journal of Experimental Criminology 13(3): 393-415.

Skogan WG (1976) Efficiency and Effectiveness in Big-City Police Departments. Public Administration Review 36(3): 278-286.

Skogan WG (2006) Community policing and "the new immigrants". Chicago. 
Slovic, P., et al., 2002. Rational actors or rational fools: Implications of the affect heuristic for behavioural economics. The Journal of Socio-Economics, 31(4), 329-342.

Slovic, P., et al., 2004. Risk as analysis and risk as feelings: Some thoughts about affect, reason, risk, and rationality. Risk analysis, 24(2), 311-322.

Smith BW and Holmes MD (2003) Community Accountability, Minority Threat, and Police Brutality: an Examination of Civil Rights Criminal Complaints. Criminology 41(4): $1035-1064$.

Smith D (1983) Police and people in London 1: A survey of Londoners. London.

Smith DJ and Gray J (1985) Police and people in London: The PSI report.

Theobald NA and Haider-Markel DP (2009) Race, bureaucracy, and symbolic representation: Interactions between citizens and police. Journal of Public Administration Research and Theory 19(2): 409-426.

Trochmann MB and Gover A (2016) Policing : An International Journal of Police Strategies \& Management Article information : Measuring the impact of police representativeness on communities 39(4): 773-790.

Turner JC and Reynolds KJ (2010) The story of social identity. In: Postmes T and Branscombe NR (eds) Rediscovering Social Identity. New York, NY: Taylor \& Francis, pp. 13-32.

Tyler TR and Blader SL (2003) The Group Engagement Model: Procedural Justice, Social Identity, and Cooperative Behavior. Personality and Social Psychology Review 7(4): $349-361$.

Tyler TR and Huo YJ (2002) Trust in the Law: Encouraging Public Cooperation with the Police and Courts. New York: Russell Sage Foundation.

Webb VJ and Marshall CE (1995) The relative importance of race and ethnicity on citizen 
attitudes toward the police (No. 2). American Journal of Police 19: 45-66.

Weitzer R (2000a) Racialized policing: residents' perceptions in three neighborhoods. Law \& Society Review 34(1): 129-155.

Weitzer R (2000b) White, black, or blue cops? Race and citizen assessments of police officers. Journal of Criminal Justice 28(4): 313-324.

Wiley S, Fleischmann F, Deaux K, et al. (2019) Why Immigrants' Multiple Identities Matter: Implications for Research, Policy, and Practice. Journal of Social Issues 75(2): josi.12329.

Wilkins VM and Williams BN (2008) Black or Blue: Racial Profiling and Representative Bureaucracy. Public Administration Review 68(4). John Wiley \& Sons, Ltd: 654-664.

Williams, M. (2001). In whom we trust: Group membership as an affective context for trust development. Academy of management review, 26(3), 377-396.

Wu Y (2014) Race/ethnicity and perceptions of the police: a comparison of White, Black, Asian and Hispanic Americans. Policing and Society 24(2). Routledge: 135-157.

Yesberg JA and Bradford B (2019) Affect and trust as predictors of public support for armed police: evidence from London. Policing and Society 29(9): 1058-1076.

Yuval F (2020) The Dynamics of the Differential Policing of Distinct Social Groups Towards a Modern Model of Policing in Diverse Societies. Policing: A Journal Of Policy And Practice. 
Table 1. Descriptive characteristics of sample

\begin{tabular}{|c|c|c|c|}
\hline Sample characteristic & & $\% *$ & $\mathrm{~N}$ \\
\hline \multirow[t]{2}{*}{ Gender } & Male & $35.8 \%$ & 93 \\
\hline & Female & $64.2 \%$ & 167 \\
\hline \multirow[t]{4}{*}{ Age range } & $18-24$ & $28.6 \%$ & 74 \\
\hline & $25-34$ & $37.5 \%$ & 97 \\
\hline & $35-49$ & $23.2 \%$ & 60 \\
\hline & $50+$ & $10.8 \%$ & 28 \\
\hline \multirow[t]{13}{*}{ Ethnicity } & Asian & $18.1 \%$ & 47 \\
\hline & Asian or Asian British - Bangladeshi & $1.9 \%$ & 5 \\
\hline & Asian or Asian British - Indian & $8.5 \%$ & 22 \\
\hline & Asian or Asian British - Pakistani & $4.2 \%$ & 11 \\
\hline & Asian or Asian British - Any other Asian background & $3.5 \%$ & 9 \\
\hline & Black & $16.5 \%$ & 43 \\
\hline & Black or Black British - African & $9.2 \%$ & 24 \\
\hline & Black or Black British - Caribbean & $6.2 \%$ & 16 \\
\hline & Black or Black British - Any other Black background & $1.2 \%$ & 3 \\
\hline & White & $65.4 \%$ & 170 \\
\hline & White - British & $53.5 \%$ & 139 \\
\hline & White - Irish & $1.9 \%$ & 5 \\
\hline & White - any other White background & $10.0 \%$ & 26 \\
\hline \multirow[t]{2}{*}{ Country of birth } & UK & $77.5 \%$ & 200 \\
\hline & Non-UK & $22.5 \%$ & 58 \\
\hline \multirow[t]{2}{*}{ Nationality } & British Citizen & $85.9 \%$ & 220 \\
\hline & Not British Citizen & $14.1 \%$ & 36 \\
\hline \multirow[t]{2}{*}{ Length lived in UK } & Less than 5 years & $7.8 \%$ & 20 \\
\hline & $5-10$ years & $4.7 \%$ & 12 \\
\hline
\end{tabular}


10-20 years

$13.3 \% \quad 34$

20 years or more

$74.2 \% \quad 190$

Region of residency

East Midlands

$5.0 \% \quad 13$

East of England

$8.9 \% \quad 23$

Greater London

$18.2 \% \quad 47$

North East England

$4.7 \% \quad 12$

North West England

$10.5 \% \quad 27$

Scotland

$8.1 \% \quad 21$

South East England

$17.1 \% \quad 44$

South West England

$8.5 \% \quad 22$

Wales

$3.1 \% \quad 8$

West Midlands

$6.2 \% \quad 16$

Yorkshire and Humber

$9.7 \% \quad 25$

*Percentages calculated with missing values excluded

Table 2. Multi-level linear regression models predicting responses to officers of different ethnic appearance

\begin{tabular}{lccccc}
\hline & Model 1 & Model 2 & Model 3 & Model 4 & Model 5 \\
& Approachable & Friendly & Respectful & Trustworthy & Aggressive \\
& $\beta(\mathrm{SE})$ & $\beta(\mathrm{SE})$ & $\beta(\mathrm{SE})$ & $\beta(\mathrm{SE})$ & $\beta(\mathrm{SE})$ \\
\hline Officer ethnic appearance (ref: Black officer) & & & & \\
White officer & $-.67(.21)^{* *}$ & $-.61(.20)^{* *}$ & $-.42(.21)^{*}$ & $-.57(.23)^{*}$ & $1.04(.25)^{* * *}$ \\
Asian officer & $-.90(.21)^{* * *}$ & $-.88(.20)^{* * *}$ & $-.80(.21)^{* * *}$ & $-.84(.22)^{* * *}$ & $.97(.24)^{* * *}$ \\
\hline Respondent ethnicity (ref: Black respondent) & & & & \\
White respondent & $.40(.24)+$ & $.49(.23)+$ & $.50(.23)^{*}$ & $.56(.25)^{*}$ & $-.54(.27)^{*}$ \\
Asian respondent & $.23(.29)$ & $.35(.28)$ & $.25(.29)$ & $.17(.31)$ & $.14(.34)$ \\
\hline Between-individual $\mathrm{R}^{2}$ & .22 & .19 & .23 & .30 & .14 \\
\hline Overall R ${ }^{2}$ & .07 & .05 & .11 & .16 & .06 \\
\hline
\end{tabular}


$+\mathrm{p}<0.1,{ }^{*} \mathrm{p}<.05, * * \mathrm{p}<.01, * * * \mathrm{p}<.001$

Unstandardised coefficients

Note: 1560 observations in 260 individuals 
Table 3. Multi-level linear regression models predicting responses to officers of different ethnic appearance - interaction between officer and respondent ethnicity

\begin{tabular}{|c|c|c|c|c|c|}
\hline & Model 1 & Model 2 & Model 3 & Model 4 & Model 5 \\
\hline & Approachable & Friendly & Respectful & Trustworthy & Aggressive \\
\hline & $\beta(\mathrm{SE})$ & $\beta(\mathrm{SE})$ & $\beta(\mathrm{SE})$ & $\beta(\mathrm{SE})$ & $\beta(\mathrm{SE})$ \\
\hline \multicolumn{6}{|c|}{ Officer ethnic appearance (ref: Black officer) } \\
\hline White officer & $-1.73(.54)^{* *}$ & $-1.65(.51)^{* *}$ & $-1.21(.54)^{*}$ & $-1.36(.58)^{*}$ & $2.13(.63)^{* *}$ \\
\hline Asian officer & $-.75(.51)$ & $-.97(.48)^{*}$ & $-.89(.50)+$ & $-1.00(.54)+$ & $1.44(.59)^{*}$ \\
\hline \multicolumn{6}{|c|}{ Respondent ethnicity (ref: Black respondent) } \\
\hline White respondent & $.15(.42)$ & $.05(.40)$ & $.24(.42)$ & $.27(.46)$ & $.07(.49)$ \\
\hline Asian respondent & $-.28(.51)$ & $-.30(.49)$ & $-.26(.51)$ & $-.45(.55)$ & $.76(.60)$ \\
\hline \multicolumn{6}{|c|}{ Officer ethnic appearance*Respondent ethnicity (ref: Black) } \\
\hline White*White & $1.17(.60)+$ & $1.16(.57)^{*}$ & $.82(.60)$ & $.87(.64)$ & $-1.41(.70)^{*}$ \\
\hline White*Asian & $1.57(.73)^{*}$ & $1.52(.69)^{*}$ & $1.30(.72)^{+}$ & $1.16(.78)$ & $-.86(.84)$ \\
\hline Asian*White & $-.27(.57)$ & $-.02(.54)$ & $.04(.56)$ & $.04(.61)$ & $-.44(.66)$ \\
\hline Asian*Asian & $.06(.71)$ & $.50(.67)$ & $.29(.70)$ & $.76(.76)$ & $-1.04(.82)$ \\
\hline Between-individual $\mathrm{R}^{2}$ & .26 & .21 & .24 & .32 & .17 \\
\hline Overall $\mathrm{R}^{2}$ & .08 & .06 & .11 & .17 & .07 \\
\hline \multicolumn{6}{|c|}{$+\mathrm{p}<0.1, * \mathrm{p}<.05, * * \mathrm{p}<.01, * * * \mathrm{p}<.001$} \\
\hline \multicolumn{6}{|c|}{ Unstandardised coefficients } \\
\hline
\end{tabular}

